\title{
STUDI PEMODELAN SISTEM PENGONTROLAN SUHU RUANGAN BERBASIS LOGIKA FUZZY SUGENO
}

\author{
Sitti Amalia ${ }^{1)}$, Rafika Andari' ${ }^{2)}$, Rudhi Syukriansyah ${ }^{3)}$ \\ ${ }^{123}$ Fakultas Teknik, Institut Teknologi Padang \\ email: rafika.andari09@gmail.com ${ }^{2}$
}

\begin{abstract}
Abstrak
Abstrak: Logika fuzzy merupakan bagian dari sistem kecerdasan buatan (Artificial Inteligent) yang mengemulasi kemampuan manusia dalam berfikir ke dalam bentuk algoritma yang kemudian dijalankan oleh mesin. Logika fuzzy juga dapat diterapkan untuk pengontrolan suhu ruangan, supaya temperatur suhu menjadi stabil. Salah satu model fuzzy logic contrroller yang diterapkan dalam menyelesaikan permasalahan adalah fuzzy Sugeno. Pembuatan prototipe ini bertujuan untuk pengambilan data logika fuzzy Sugeno dengan alat ini agar suhu dalam suatu ruangan menjadi stabil sesuai dengan yang diinginkan, sistem kerja prototipe ini berdasarkan nilai suhu dan kelembaban yang terbaca oleh sensor kemudian kipas akan berputar sesuai dengan suhu dan kelembabannya. Penelitian ini menggunakan logika fuzzy sugeno dengan input suhu dan kelembaban dan output-nya berupa putaran kipas. Rangkaian Pemodelan sistem Pengontrolan Suhu Ruangan Berbasis Logika fuzzy sugeno yang dirancang mampu mengatur kondisi suhu ruangan untuk setiap kondisi suhu dan kelembaban yang terbaca oleh sensor. Percobaan hasil untuk perbandingan antara perhitungan manual dengan matlab mencapai angka 100\% keberhasilan. Sedangkan Percobaan hasil untuk perbandingan antara matlab dan prototipe memiliki rata-rata error sebesar 36\% dari lima kali percobaan.
\end{abstract}

Kata kunci: logika fuzzy, metode Sugeno, fuzzyfikasi, defuzzyfikasi, fungsi implikasi.

Abstract: Fuzzy logic is part of an artificial intelligence system (Artificial Intelligence) that emulates the human ability to think in the form of an algorithm which is then run by a machine. Fuzzy logic can also be applied to control room temperature, so that the temperature becomes stable. One of the fuzzy logic controller models that is applied in solving the problem is Fuzzy Sugeno. Making this prototype aims to collect Sugeno fuzzy logic data with this tool so that the temperature in a room becomes stable as desired, this prototype work system is based on the temperature and humidity values read by the sensor then the fan will rotate according to the temperature and humidity. This research uses Sugeno fuzzy logic with temperature and humidity input and the output is fan rotation. The series of modeling system for room temperature control based on Sugeno fuzzy logic, which is designed to be able to regulate room temperature conditions for each temperature and humidity condition read by the sensor. Experimental results for the comparison between manual calculation and Matlab achieved $100 \%$ success. While the experimental results for the comparison between matlab and prototype have an average error of $36 \%$ from five experiments.

Keywords: fuzzy logic, Sugeno method, fuzzyfication, defuzzyfikasi, function implications.

\section{PENDAHULUAN}

Sistem kendali dengan nilai input nonlinier dan persamaan fungsi alih yang sulit, membutuhkan suatu perancangan sistem kendali yang mampu membuat keputusan pengendaliannya. Hal ini dikarenakan bahwa keputusan pengendalian yang dihasilkan oleh logika manusia mempunyai keluaran pengendalian yang sempurna dalam pengaturan segala sesuatunya, baik itu yang konvensional maupun non-konvensional (A. Sofwan, 2005).

Salah satu aplikasi dari bidang sistem kendali yang berlandaskan sistem logika yang digunakan para konsumen dalam mengambil keputusan adalah fuzzy logic contrroller (FLC). FLC merupakan suatu 
metode berhitung menggunakan variabel kata-kata (linguistic variable) sebagai pengganti berhitung menggunakan bilangan. Kata-kata yang digunakan dalam fuzzy logic memang tidak seteliti bilangan, namun kata-kata jauh lebih dekat dengan intuisi manusia (Nurdani Febrianto, 2016).

Logika fuzzy merupakan bagian dari sistem kecerdasan buatan (Artificial Inteligent) yang mengemulasi kemampuan manusia dalam berfikir ke dalam bentuk algoritma yang kemudian dijalankan oleh mesin. Algoritma ini banyak digunakan dalam berbagai aplikasi pemprosesan data yang tidak dapat direpresentasikan dalam bentuk biner (Sri Kusumadewi, 2002). Logika fuzzy sendiri memiliki derajat keanggotaan dalam rentang 0 hingga 1 . Lain halnya dengan logika digital yang hanya memiliki dua nilai 1 atau 0 . Logika fuzzy juga digunakan untuk menerjemahkan suatu besaran yang diekspresikan menggunakan bahasa (linguistic), logika fuzzy menggambarkan sejauh mana suatu nilai itu benar dan sejauh mana suatu nilai itu salah. Logika fuzzy suatu cara yang tepat untuk memetakan suatu ruang input ke dalam suatu ruang output (Siti Abidah, 2016).

Logika fuzzy juga dapat diterapkan untuk pengontrolan suhu ruangan, supaya suhu menjadi stabil. Salah satu model fuzzy logic contrroller yang diterapkan dalam menyelesaikan permasalahan adalah fuzzy sugeno (P.A. Hancock $d k k$, 2003). Dimana logika fuzzy sugeno merupakan suatu metode dalam mengambil keputusan sangat fleksibel dan memiliki toleransi pada data yang ada (Rizky Pahlevi $d k k, 2013$ ).

Fuzzy metode Sugeno merupakan metode inferensi fuzzy untuk aturan yang direpresentasikan dalam bentuk if-then, dimana output sistem tidak berupa himpunan fuzzy, melainkan berupa konstanta atau persamaan linier (Agus Naba, 2009).
Penelitian sebelumnya, yang terkait dengan penerapan logika fuzzy diantaranya:

1. Room Heater Control Berbasis Fuzzy Logic Controller (FLC), 2017 menggunakan kendali fuzzy memiliki batasan-batasan lebih luas sehingga memudahkan pengaturan dalam jarakjarak tertentu demi mendapatkan hasil yang maksimal dan akurat. Sistem yang dibuat untuk kali ini adalah sistem replika dari kontrol pemanas yang digunakan seperti pada penetas telur. Sistem bekerja dengan menggunakan input berupa sensor suhu LM35 sejumlah dua buah. Satu buah sensor ditempatkan di luar sebagai kendali suhu luar ruangan dan satu sensor diletakkan di dalam ruangan sebagai kendali temperatur dalam ruangan (Aprilia Dwi Nugroho $d k k$, 2017).

2. Menggunakan Kontrol fuzzy logic controller untuk pengaturan suhu cairan berbasis atmega16, 2002. Metode kontrol yang digunakan yang digunakan dalam pengendalian suhu saat proses pemanasan (heating) adalah kendali fuzzy. Settling point suhu yang diinginkan pada proses pembuatan sari buah adalah $63^{\circ} \mathrm{C}-74^{\circ} \mathrm{C}$, dengan lama pemanasan sekitar 15-30 menit. Hasil pengujian diperoleh bahwa pengendalian suhu heater menggunakan teknik kendali fuzzy pada alat pembuatan sari buah otomatis menghasilkan respon sistem dengan rise time dan settling time yang kecil serta nilai maksimum overshoot yang masih dalam batas toleransi yakni $5 \%$ (Zulkifli, 2002).

3. Desain dan Purwarupa Fuzzy Logic Control untuk Pengendalian Suhu Ruangan, 2017. Pengujian sistem ini dilakukan dengan membandingkan hasil keluaran pengendali melalui simulasi Fuzzy Logic Toolbox yang tersedia pada Matlab. Dua unit purwarupa dirancang dengan sensor masukan yang berbeda sebagai 
perbandingan. Hasilnya menunjukkan bahwa purwarupa sistem pertama dan kedua mampu mengendalikan suhu ruangan dengan rata-rata kesalahan berturut-turut $1,31 \%$ dan $4,06 \%$ jika dibandingkan dengan simulasi Matlab (Faisal Wahab, 2017).

4. Perancangan Sistem Kendali Suhu Dan Kelembaban Ruangan Berbasis Arduino Uno Dengan Metoda Logika Fuzzy Tsukamoto. Dari hasil penelitian yang telah dilakukan selama 1 jam, penggunaan fuzzy logic sebagai kendali exhaust mampu menghemat daya $16 \%$ dibandingkan dengan tanpa kontrol fuzzy. Sementara batas yang ingin dicapai yaitu $15 \%$. Selain itu kendali yang digunakan mampu mendekati suhu ideal ruangan yaitu $26,5^{\circ} \mathrm{C}$ dari standar suhu ruangan ideal yaitu $26^{\circ} \mathrm{C}$ (Reza Muaz Hadrul, 2018).

Berdasarkan hal di atas, diperlukan merancang sebuah alat sistem kendali suhu yang dapat mengontrol suhu secara otomatis dan dihubungkan dengan mikrocontroller dengan kontrol logika fuzzy sebagai pengendalinya, karena logika fuzzy adalah suatu cara yang tepat untuk memetakan suatu ruang input kedalam suatu ruang output, mempunyai nilai kontinyu, dan logika fuzzy memiliki toleransi terhadap data yang kurang tepat.

Tujuan dari penelitian yang dilakukan ini adalah merancang prototipe pengendali suhu ruangan menggunakan metode penalaran logika fuzzy Sugeno yang dapat diimplementasikan dengan metode penalaran secara manual, menggunakan matlab dan menggunakan prototipe. Logika fuzzy Sugeno sangat baik digunakan karena merupakan salah satu metode pengontrolan suhu ruangan agar suhu menjadi stabil, selain itu juga sangat fleksibel dalam mengambil keputusan serta memiliki toleransi pada data yang ada
(Kusumadewi, 2004), (Kusumadewi, 2010).

\section{METODE PENELITIAN}

Jenis penelitian ini adalah perancangan dan pembuatan alat sistem kendali suhu untuk mengkaji tentang kondisi temperatur suhu di dalam ruangan. Kondisi yang sekarang ini kita tidak bisa mengetahui suhu ruangan tersebut, sehingga terkadang kita merasa kepanasan di dalam ruangan, maka pada kondisi ini lah dirasa perlu alat sistem pengendalian suhu.

Lokasi kajian penelitian ini dilaksanakan di ruangan Institut Teknologi Padang.

Untuk terpenuhinya kebutuhan data pada penelitian yang dilakukan, maka diperlukan sebagai berikut:

1. Data hasil pengukuran Prototipe

2. Data perhitungan manual

3. Data perhitungan pada matlab.

Adapun alat dan bahan yang dibutuhkan dalam penelitian ini adalah:

1. Hardware
a. PC Programming (Laptop)
b. Arduino Uno
c. Sensor Suhu (DHT11)
d. LCD $2 \times 16$
e. $\mathrm{I} 2 \mathrm{C}$
f. Trafo $1 \mathrm{~A}$
g. Driver motor L289N
h. Dioda
i. Kebel Jumper

2. Software
a. Matlab R12
b. Proteus 8 profesional

Perakitan prototipe dimulai dengan melakukan simulasi rangkaian pada proteus. Dengan menggunakan bantuan software Proteus 8 Profesional. Selanjutnya, komponen dipasang dan disolder sesuai dengan skema. Program kemudian di-compile untuk mengetahui apakah sudah benar atau belum, dan dapat di-upload ke arduino Uno dengan bantuan penghubung mini USB untuk selanjutnya program serta hardware-nya dapat diuji apakah sudah berhasil atau 
belum.

Selanjutnya, pengujian prototipe dilakukan menggunakan multimeter sebagai alat pengukuran tegangan pada prototipe. Multimeter dikalibrasi dan diatur tombol pada DCV 10. Kabel (+) dan kabel (-) diletakkan pada output kipas prototipe yang ada di modul driver motor. Kemudian dicatat berapa tegangan yang dihasilkan sesuai dengan nilai yang diinputkan. Nilai tegangan yang dihasilkan tersebut dilakukan perbandingan antara hasil manual, matlab dan prototipe. Proses pengambilan data penelitian ini disajikan seperti pada Gambar 1.

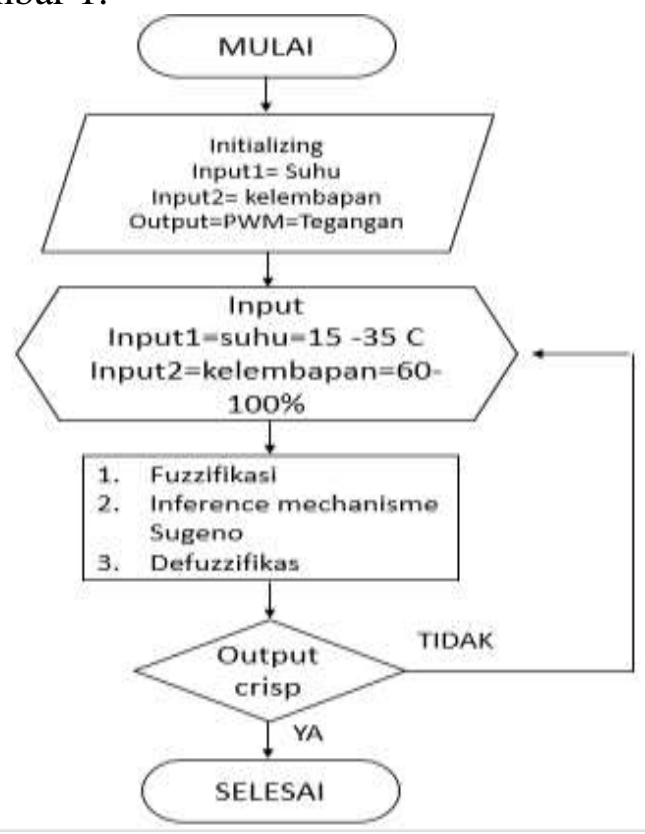

Gambar 1. Flowchart Pengambilan Data

Berdasarkan Gambar 1. flowchart rangkaian dapat dilihat bahwa langkah pertama adalah memulai simulasinya, langkah kedua yaitu proses input data atau informasi dimana input 1 (suhu) input 2 (kelembapan) dan output adalah tegangan/PWM, langkah ketiga melakukan proses inisialisasi berbentuk pemberian nilai pada input 1 (suhu) 1535C dan input 2 (kelembapan) 60-100\%, langkah keempat melakukan proses perhitungan dan pengolahan data terdiri dari (fuzzifikasi, inference mechanisme sugeno, defuzzifikasi), langkah kelima melakukan perbandingan pernyataan yang dimana memberikan pilihan untuk langkah selanjutnya jika output crips hasil perbandingannya sama atau sesuai maka langsung selesai jika tidak atau mau mencari input lain maka akan kembali ke langkah ketiga melakukan proses input kembali.

\section{HASIL DAN PEMBAHASAN}

Rangkaian kontrol memiliki peran yang sangat penting dari pada sistem alat ini, karena disinilah katup akan dikontrol dan melihat suhu ruangan dan mendeteksi kelembaban yang akan terdeteksi pada alat nanti. Skema rangkaian Kontrol Pengendali Suhu ruangan disajikan pada gambar 2.

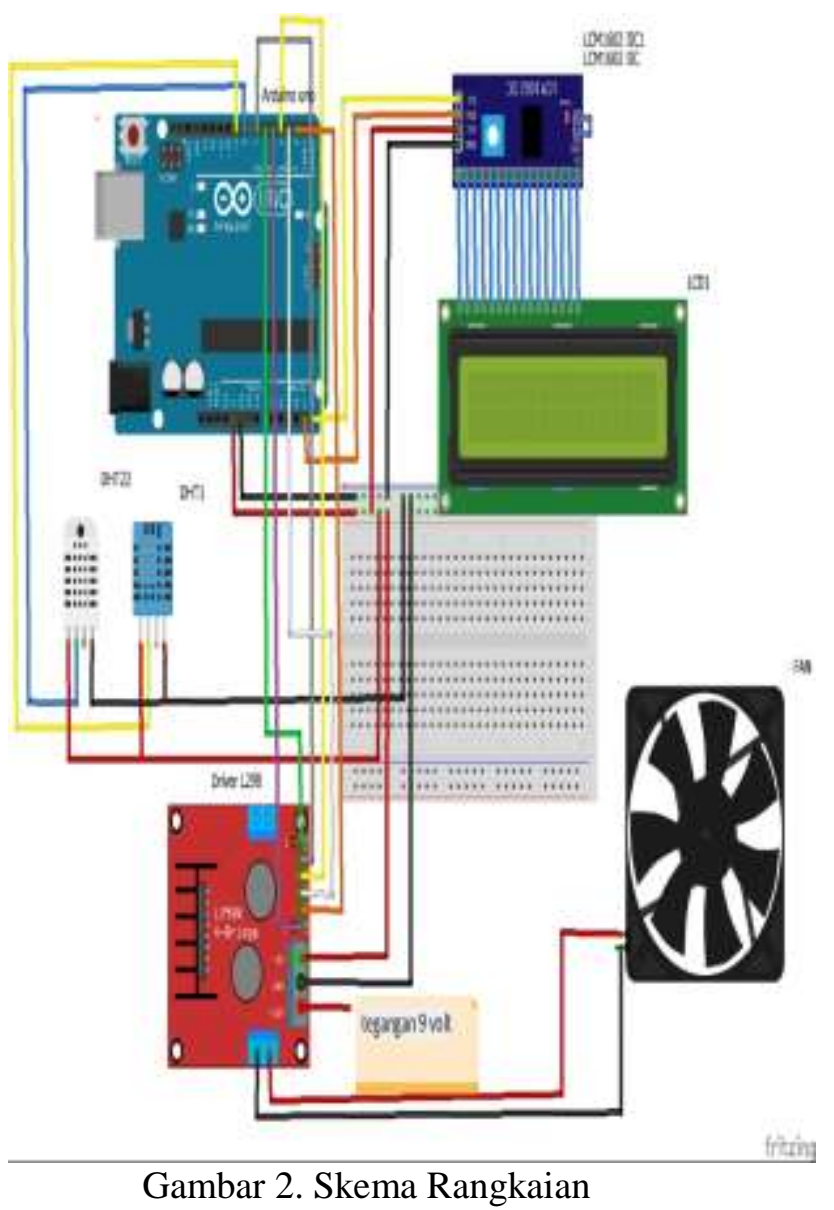

\section{A. Percobaan pada Matlab}

Hasil percobaan secara manual seperti pada Tabel 1. Pada suhu rendah $\left(24^{0} \mathrm{C}\right)$ diperoleh nilai kelembaban paling rendah sebesar $79 \%$ dan nilai tegangannya $3,92 \mathrm{~V}$. Nilai kelembaban terbesar diperoleh 
pada suhu $31^{\circ} \mathrm{C}$ yaitu $92 \%$ dan tegangan $5,8 \mathrm{~V}$. Akan tetapi, pada suhu paling tinggi $\left(34^{\circ} \mathrm{C}\right)$ nilai kelembaban berkurang $6 \%$ dari pengukuran sebelumnya, sedangkan nilai tegangan diperoleh paling tinggi sebesar $6,72 \mathrm{~V}$.

\begin{tabular}{cccc}
\multicolumn{4}{c}{ Tabel 1. Hasil Percobaan Matlab } \\
\hline No & \multicolumn{2}{c}{ Input Value } & $\begin{array}{c}\text { Output } \\
\text { Value }\end{array}$ \\
\cline { 2 - 4 } & Suhu $\left({ }^{\circ} \mathrm{C}\right)$ & $\begin{array}{c}\text { Kelembaban } \\
(\%)\end{array}$ & Manual \\
\hline 1 & 24 & 79 & $3,92 \mathrm{~V}$ \\
2 & 28 & 88 & $5,04 \mathrm{~V}$ \\
3 & 29 & 81 & $5,32 \mathrm{~V}$ \\
4 & 31 & 92 & $5,8 \mathrm{~V}$ \\
5 & 34 & 86 & $6,72 \mathrm{~V}$ \\
\hline
\end{tabular}

\section{B. Percobaan Alat Prototipe Pengendali Suhu Ruangan}

Hasil percobaan alat pengendali suhu ruangan yang diperoleh berdasarkan pada Tabel 2. Pada suhu rendah $\left(24^{0} \mathrm{C}\right)$ diperoleh nilai kelembaban paling rendah sebesar $79 \%$ dan nilai tegangannya $4,3 \mathrm{~V}$. Nilai kelembaban terbesar diperoleh pada suhu $31^{\circ} \mathrm{C}$ yaitu $92 \%$ dan tegangan $6,4 \mathrm{~V}$. Akan tetapi, pada suhu paling tinggi $\left(34^{0} \mathrm{C}\right)$ nilai kelembaban berkurang $6 \%$ dari pengukuran sebelumnya, sedangkan nilai tegangan diperoleh paling tinggi sebesar 6,6 V. Semakin besar nilai input suhu yang digunakan, maka nilai tegangan yang diperoleh semakin besar pula.

Tabel 2. Percobaan Alat Prototipe Pengendali Suhu Ruangan

\begin{tabular}{lccc}
\hline No & & Input Value & Output Value \\
\cline { 2 - 4 } & Suhu( $\left({ }^{\circ} \mathrm{C}\right)$ & $\begin{array}{c}\text { Kelembaban } \\
(\%)\end{array}$ & Alat \\
\hline 1 & 24 & 79 & $4,3 \mathrm{~V}$ \\
2 & 28 & 88 & $5,6 \mathrm{~V}$ \\
3 & 29 & 81 & $5,7 \mathrm{~V}$ \\
4 & 31 & 92 & $6,4 \mathrm{~V}$ \\
5 & 34 & 86 & $6,6 \mathrm{~V}$ \\
\hline
\end{tabular}

\section{Hasil Percobaan Fuzzy}

Berdasarkan pada tabel 3. Dapat dilihat untuk perbandingan hasil perbandingan antara matlab dan prototipe dari lima kali percobaan memiliki rata-rata error sebesar $36 \%$.

Tabel 3. Perbandingan matlab dengan alat (prototipe)

\begin{tabular}{|c|c|c|c|c|c|}
\hline \multirow{2}{*}{$\begin{array}{l}\mathrm{N} \\
0\end{array}$} & \multicolumn{2}{|c|}{ Inpt Value } & \multirow{2}{*}{$\begin{array}{c}\text { Outpit Value } \\
\text { Prolotipe }\end{array}$} & \multirow{2}{*}{$\begin{array}{c}\text { Oufpul Value } \\
\text { Mariab }\end{array}$} & \multirow[t]{2}{*}{ Ence } \\
\hline & Suhu'C & $\begin{array}{c}\text { Relembap } \\
\text { in } \times \text {. }\end{array}$ & & & \\
\hline 1 & 24 & 79 & $43 \mathrm{~V}$ & $392 \mathrm{~V}$ & 0.38 \\
\hline 2 & 28 & 88 & $5.6 \mathrm{~V}$ & $5,04 \mathrm{~V}$ & 0.56 \\
\hline 3 & 29 & 81 & $5.7 \mathrm{~V}$ & $5,32 \mathrm{~V}$ & 038 \\
\hline 4 & 31 & 92 & $64 \mathrm{~V}$ & $5,8 \mathrm{~V}$ & 0.6 \\
\hline 5 & 34 & 86 & $6.6 \mathrm{~V}$ & $6,72 \mathrm{~V}$ & -0.12 \\
\hline \multicolumn{5}{|c|}{ Junloh } & 1.8 \\
\hline
\end{tabular}

Hasil percobaan yang terdapat pada tabel 4. dapat dianalisa bahwa perbandingan antara perhitungan manual dan matlab dari lima perhitungan tidak memiliki error. Maka perhitungan manual dan matlab memiliki tingkat keberhasilan $100 \%$.

Tabel 4. Perbandingan Antara Manual Dan Matlab

\begin{tabular}{|c|c|c|c|c|c|}
\hline \multirow[t]{2}{*}{ No } & \multicolumn{2}{|c|}{ Input Valus } & $\begin{array}{l}\text { Outpat } \\
\text { Valbe }\end{array}$ & Outpe Value & \multirow[t]{2}{*}{ Entrof 5} \\
\hline & Sthurc & Kelembapan $\%$ & Marual & Matlab & \\
\hline 1 & 24 & 79 & $3,92 \mathrm{~V}$ & $392 \mathrm{~V}$ & 0 \\
\hline 2 & 28 & 88 & $5,04 \mathrm{~V}$ & $5,04 \mathrm{~V}$ & 0 \\
\hline 3 & 29 & 81 & $5,32 \mathrm{~V}$ & $5,32 \mathrm{~V}$ & 0 \\
\hline 4 & 31 & 92 & $5,8 \mathrm{~V}$ & $5.8 \mathrm{~V}$ & 0 \\
\hline 5 & 34 & 86 & $6,72 \mathrm{~V}$ & $6,72 \mathrm{~V}$ & 0 \\
\hline
\end{tabular}

\section{KESIMPULAN}

Dari pembuatan alat, pengujian dan analisa yang dibuat, didapatkan beberapa kesimpulan :

1. Penerapan logika fuzzy sugeno pada matlab dan prototipe pengendalian suhu ruangan telah berhasil dibuat sesuai yang diharapkan.

2. Dari 5 (lima) kali percobaan matlab dan perhitungan manual memiliki persamaan tingkat keberhasilan $100 \%$ serta perbandingan antara prototipe dan matlab dari lima kali percobaan memiliki error tertinggi sebesar $36 \%$. 
Untuk penelitian selanjutnya sebaiknya menggunakan sensor tegangan pada output driver motor L289N, supaya memudahkan untuk mengetahui berapa tegangn pada output. Alat ini sebaiknya dirancang dengan menggunakan box berbentuk miniatur rumah supaya komponen tidak mudah goyang dan ketika melakukan percobaan tidak mudah rusak atau error.

\section{DAFTAR PUSTAKA}

A. Sofwan. 2005. Penerapan Fuzzy Logic Pada Sistem Pengaturan Jumlah Air Berdasarkan Suhu dan Kelembaban. Seminar Nasional Aplikasi Teknologi Informasi 2005 (SNATI 2005).

Abidah, Siti. 2016. Analisis Komparasi Metode Tsukamoto dan Sugeno dalam Prediksi Jumlah Siswa Baru, Volume 8 No 2 hal 3: Journal Speed2016.

Jurnal P.A. Hancock dan I. Vasmatzidis (2003:356).

Kusumadewi, Sri. 2002. Analisis Desain Sistem Fuzzy menggunakan Tool Box Matlab. Jogjakarta: Graha Ilmu.

Kusumadewi, S. dan Purnomo, H, 2004, Aplikasi Logika Fuzzy: Untuk Pendukung Keputusan, Graha Ilmu, Yogyakarta.

Kusumadewi, S \& H. Purnomo. 2010. Aplikasi Logika Fuzzy untuk Pendukung Keputusan edisi 2. Yogyakarta: Graha Ilmu.

Naba, Agus. 2009. Belajar Cepat Fuzzy Logic Menggunakan MATLAB. Yogyakarta : ANDI.

Nugroho, Aprilia Dwi. 2017. Room Heater Control Berbasis Fuzzy Logic Controller (FLC). Skripsi, Pendidikan Teknik Mekatronika,
Universitas Negeri Yogyakarta.

Nurdani, Febrianto. 2016. Rancang Bangun Kontrol Suhu Air Pada Prototipe Pemanas Air Menggunakan Logika Fuzzy. Tugas akhir Teknik Elektro Fakultas Teknik Elektro, Universitas Telkom.

Pahlevi, Rizky, Widyarto, Wahyu Oktri, Tb. Ai Munandar. (2013). Implementasi Fuzzy Mamdani untuk Penentuan Pengadaan Kartu Operator pada Distributor Kartu Perdana PT. XYZ. Prosiding Seminar Nasional Industrial Service (SNIS) III. Fakultas Teknik Universitas Serang Raya.

Reza, Muaz Hadrul. 2018. Perancangan Sistem Kendali Suhu Dan Kelembaban Ruangan Berbasis Arduino Uno Dengan Metoda Logika Fuzzy Tsukamoto. Diploma Thesis, Universitas Andalas.

Wahab, Faisal. 2017. Desain dan Purwarupa Fuzzy Logic Control untuk Pengendalian Suhu Ruangan. JTERA (Jurnal Tknologi Rakayasa) Vol. 2 NO.1 Juni 2017. DOI: $10.31544 /$ jtera.v2.i1.2017.1-8

Zulkifli, Helmi Puri. (2002). Penerapan Logika Fuzzy untuk Menentukan Jumlah Produk (Studi Kasus di PT. Friesche Vlag Jakarta Indonesia). Skripsi: Universitas Islam Indonesia, Yogyakarta. 